University of Montana

ScholarWorks at University of Montana

$3-2012$

\title{
Why Are Caribou Declining in the Oil Sands?
}

Stan Boutin

Mark S. Boyce

Mark Hebblewhite

University of Montana - Missoula, mark.hebblewhite@umontana.edu

Follow this and additional works at: https://scholarworks.umt.edu/wildbio_pubs

Part of the Life Sciences Commons

Let us know how access to this document benefits you.

\section{Recommended Citation}

Boutin, Stan; Boyce, Mark S.; and Hebblewhite, Mark, "Why Are Caribou Declining in the Oil Sands?" (2012). Wildlife Biology Faculty Publications. 22.

https://scholarworks.umt.edu/wildbio_pubs/22

This Editorial is brought to you for free and open access by the Wildlife Biology at ScholarWorks at University of Montana. It has been accepted for inclusion in Wildlife Biology Faculty Publications by an authorized administrator of ScholarWorks at University of Montana. For more information, please contact scholarworks@mso.umt.edu. 


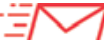

\section{Why are caribou declining in the oil sands?}

Peer-reviewed letter

Conservation of woodland caribou (Rangifer tarandus caribou; hereafter caribou) is challenging in Alberta's rapidly developing oil sands region. In the December issue (Front Ecol Environ 2011; 9[10]: 546-51), Wasser et al. made two unexpected claims: (1) caribou conservation is less urgent than previously thought because numbers are stable and well above provincial estimates, and (2) stress caused by human activity, and not wolf (Canis lupus) predation, is the proximate cause of caribou decline. We think the conclusions made by Wasser et al. are flawed, thereby obfuscating their management recommendations.

Caribou population estimates obtained by Wasser et al. could be biased (artificially high) because of genotyping error such as that caused by allelic dropout, where there is preferential amplification of one of the two alleles at a locus (Schwartz and Monfort 2008). Wasser et al. reported a very high allelic dropout, and even low levels of genotyping error $(1-5 \%)$ can cause severe overestimation of abundance (up to 5.5 times; Creel et al. 2003; McKelvey and Schwartz 2004). Although adopting some measures to screen against genotyping errors, Wasser et al. did not report if they tested for or removed errors, nor did they use capture-mark-recapture estimators that explicitly incorporate genotyping error (Lukacs and Burnham 2005).

Wasser et al. indicated caribou populations may not be in rapid decline because they detected no significant change in caribou population size between 2006 and 2009. Estimating population change over short time intervals is unreliable when confidence limits are as wide as their 2006 estimate. Long-term data collected on caribou vital rates (female survival and recruitment) in the oil sands region suggest drastic declines in the East Side of the Athabasca
River (ESAR) and adjacent herds over the past 15 years (Figure 1; Latham et al. 2011a). Despite uncertainty around annual growth rate estimates, the long-term vital rates paint a picture of substantial decline.

What is causing the caribou populations to decline so rapidly? Centuries of coexistence between wolves and caribou have been possible because caribou lived at low densities in peatlands and mature conifer forest, whereas wolves - and their main prey, moose (Alces alces) - were found in upland habitats. In the oil sands region, human-mediated habitat and climate change has led to the addition of deer (Odocoileus spp) to the system, causing wolf density to double; moreover, wolf use of linear features created by the energy sector has increased wolf use of caribou range (Latham et al. 2011, a and b). Although wolves spend most of their time hunting and consuming the most abundant prey (now deer), the presence of more wolves in caribou range has increased incidental predation on caribou, primarily during summer, resulting in caribou population declines. Through the action of their shared predator, an increase in deer causes a decline in caribou, a phenomenon known as "apparent competition" (Figure 2; Holt 1977; DeCesare et al. 2010).

Wasser et al. found that wolves predated mostly on deer and were "drawn away" from caribou habitat in favor of deer habitat, interpreting this to imply that wolf predation is unimportant for caribou. Measuring the diet and habitat use of wolves at a single point in time fails to capture important changes in predator-prey dynamics that have occurred in the system. Indeed, Wasser et al.'s findings, along with the high numbers of wolves they report, are consistent with long-term studies in the region (Latham et al.
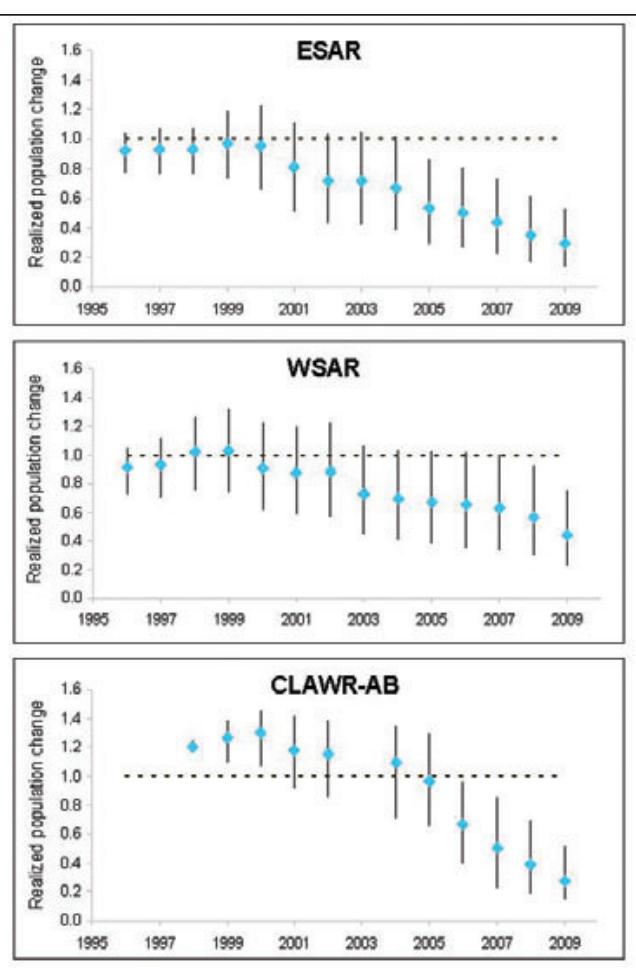

Figure 1. Realized population change in three caribou herds in the oil sands region of Alberta (ESAR, WSAR [West Side of the Athabasca River], CLAWR-AB [Cold Lake Air Weapons Range-Alberta Side]). We estimated changes in population size relative to the initial year of monitoring by following the procedure outlined in Anthony et al. (2004) for spotted owls (Strix occidentalis caurina) using the equation developed by Hatter and Bergerud (1991) to calculate annual $\lambda$ values. We generated error estimates (error bars are $95 \%$ confidence intervals) around realized population change for each year by drawing randomly from a log-normal distribution of annual $\lambda$ (ie mean and standard deviation) 10000 times using the Monte Carlo PopTools extension for Microsoft Excel. The information is based on 1382 caribou-years with an average of 24-30 females monitored per year per herd.

2011a) and elsewhere in caribou range (Wittmer et al. 2007) documenting the importance of changing predator-prey dynamics, apparent competition, and incidental predation for caribou populations.

Wasser et al. based their claim that stress caused by human activity is the cause of caribou declines on their finding that caribou near oil exploration roads showed higher levels of stress and that stress levels dropped when oil crews left the area. Sample collection was completed by mid- 
March but oil crews did not leave until 10 March, meaning that the samples had to come from caribou still exposed to high human activity and suggesting that the changes observed were due to some other factor. Further, Wasser et al. provided no evidence for any causal link between the stress levels they measured and caribou population decline. Stress levels have not led to reduced body condition, given that 97 of 104 female caribou captured in February (2007-2011) in the region were scored as being in good to excellent condition (Alberta Caribou Committee unpublished data).

Wasser et al. recommended that actions to conserve caribou should focus on minimizing creation of secondary roads and consolidating traffic to minimize stress to caribou. In fact, energy and forestry companies have adopted an Integrated Land Management approach to minimize the size, duration, and intensity of their activities, which is precisely the approach suggested by Wasser et al. Unfortunately this has been insufficient to slow caribou decline (Figure 1). Wasser et al. incorrectly cited Schneider et al. (2010) as stating that removal of wolves is "the most effective tool to curb" caribou declines in the region. That article and provincial caribou recovery plans suggest three actions must be implemented together: caribou habitat protection; restoration of seismic lines, well sites, and secondary roads to natural vegetation; and predator management. The lattermost is necessary because habitat protection and restoration will take too long to restore conditions that would reduce deer, moose, and wolf densities allowing caribou populations to increase. Wasser et al. were correct that wolf control has potential problems but used incorrect inferences to discount apparent competition as a cause of caribou decline. It is therefore unlikely that Wasser et al.'s recommendations would reverse caribou declines in Alberta.

Stan Boutin ${ }^{1 *}$, Mark S Boyce ${ }^{1}$, Mark Hebblewhite ${ }^{2}$, Dave Hervieux ${ }^{3}$, Kyle H Knopff ${ }^{4}$,

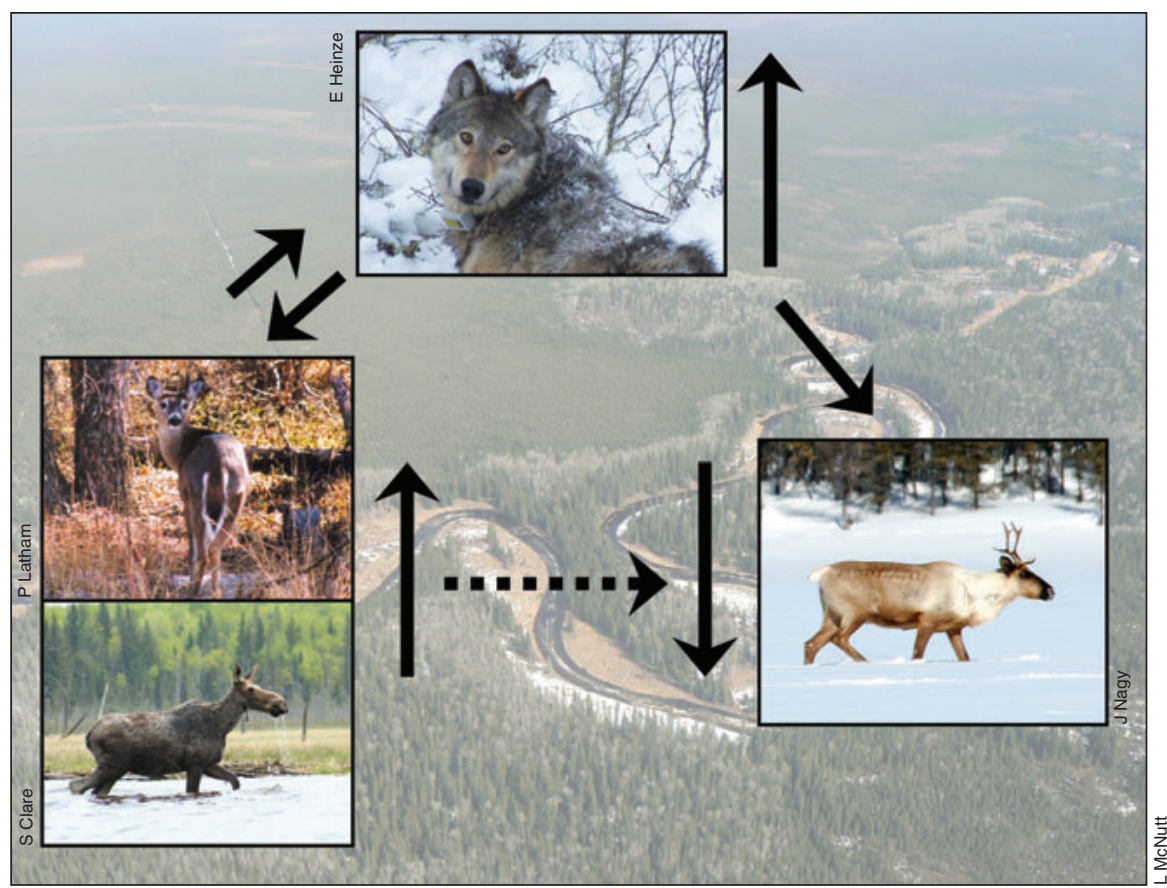

Figure 2. Prey enrichment, apparent competition, and incidental predation in caribou populations in the oil sands region of Alberta. Populations of wolves and their primary prey, moose, are tightly linked because moose form the bulk of the wolf's diet. Creation of early successional forest by human land use and changing climate has enriched prey biomass in the system by the addition of deer, which has increased wolf densities because wolves have incorporated deer into their diet. Increased wolf numbers have strong effects on caribou numbers by increasing mortality of calves and adults in summer. There is no feedback between caribou and wolves or between caribou and the other ungulates because caribou represent a small proportion of the total ungulate biomass and comprise a small proportion of the wolf diet. Thus, moose and deer numbers affect caribou numbers negatively through the action of their shared predator, the wolf, but not vice versa.

\section{Cecilia Latham ${ }^{1}$, A David M} Latham $^{5}$, John Nagy ${ }^{1}$, Dale Seip ${ }^{6}$, and Robert Serrouya ${ }^{1}$

${ }^{1}$ Department of Biological Sciences, University of Alberta, Edmonton, Alberta, Canada*(sboutin@ualberta.ca); ${ }^{2}$ Wildlife Biology Program, Department of Ecosystem and Conservation Sciences, College of Forestry and Conservation, University of Montana, Missoula, MT; ${ }^{3}$ Fish and Wildlife Division, Government of Alberta, Grande Prairie, Alberta, Canada; ${ }^{4}$ Golder Associates Ltd, Calgary, Alberta, Canada; ${ }^{5}$ Landcare Research, Lincoln, New Zealand; ${ }^{6}$ British Columbia Ministry of Environment, Prince George, British Columbia, Canada

Anthony RG, Forsman ED, Franklin AB, et al. 2004. Status and trends in demography of northern spotted owls, 1985-2003. Wildl Monogr 163: 1-48.

Creel S, Spong G, Sands JL, et al. 2003.
Population size estimation in Yellowstone wolves with error-prone noninvasive microsatellite genotypes. Mol Ecol 12: 2003-09.

DeCesare N, Hebblewhite M, Robinson H, et al. 2010. Endangered, apparently: the role of apparent competition in endangered species conservation. Anim Conserv 13: 353-62.

Hatter IW and Bergerud WA. 1991. Moose recruitment, adult mortality, and rate of change. Alces 27: 65-73.

Holt RD. 1977. Predation, apparent competition and the structure of prey communities. Theor Pop Biol 12: 197-229.

Latham ADM, Latham MC, McCutchen NA, et al. 2011a. Invading white-tailed deer change wolf-caribou dynamics in northeastern Alberta. J Wildl Manage 75: 204-12.

Latham ADM, Latham MC, Boyce MS, and Boutin S. 2011b. Movement responses by wolves to industrial linear features and their effect on woodland caribou in northeastern Alberta. Ecol Appl 21: 2854-65.

Lukacs PM and Burnham KP. 2005. Review of capture-recapture methods applicable to noninvasive genetic sampling. Mol Ecol 14: 3909-19.

McKelvey KS and Schwartz MK. 2004. 
Genetic errors associated with population estimation using non-invasive molecular tagging: problems and new solutions. J Wildl Manage 68: 439-48.

Schneider RR, Hauer G, Adamowicz WL, et al. 2010. Triage for conserving populations of threatened species: the case of woodland caribou in Alberta. Biol Conserv 143: 1603-11.

Schwartz MK and Monfort SL. 2008. Genetic and endocrine tools for carnivore surveys. In: Long R, Mackay $\mathrm{P}$, Zielinski W, and Ray J (Eds). Noninvasive survey methods for carnivores. Washington, DC: Island Press.

Wittmer HU, McLellan BN, Serrouya R, et al. 2007. Changes in landscape composition influence the decline of a threatened woodland caribou population. J Anim Ecol 76: 568-79.

doi:10.1890/12.WB.005

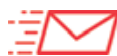

\section{To kill or not to kill - that is the question}

Although Boutin et al. questioned our methodology and conclusions (Front Ecol Environ 2011; 9[10]: 546-51), we contend that their concerns are unjustified.

First, Boutin et al. argued that a high allelic dropout rate may have exaggerated our DNA-based population estimates, referring to our rate per amplification. However, we controlled the allelic dropout rate by repeated amplification of multiple extracts per sample; both individual identification errors and coalescent misidentifications (shadow effects) occurred at a rate of once per 1865 genotypings (see WebPanel 1 in our original paper), which would bias our population estimate by less than one individual.

Boutin et al. also argued that "longterm data collected on caribou vital rates (female survival and recruitment) in the oil sands region suggest drastic declines in [populations]". Boutin et al. and Latham et al. (2011) used a "lambda method" to estimate long-term population change in caribou by multiplying a series of annual estimates of realized growth rate from 1993 to 2009, following Hatter and Bergerud (1991) and Anthony et al. (2004). However, this estimator should be based on precise and unbiased estimators of vital rates, used only for a short time horizon, with recalibration by population abundance esti-

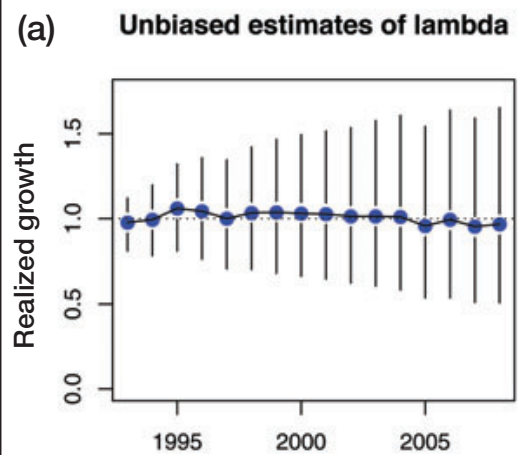

(c) $4 \%$ biased estimates of lambda

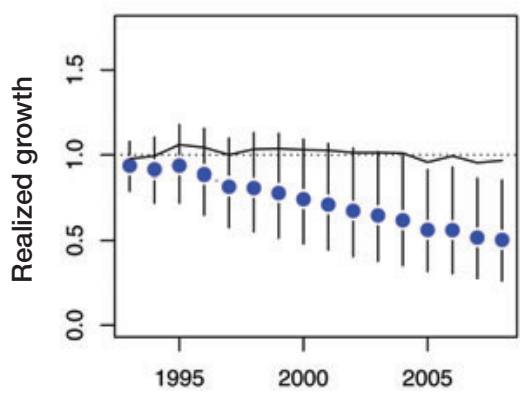

(b) $2 \%$ biased estimates of lambda

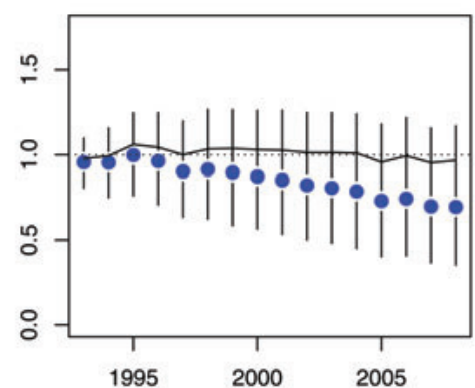

(d) $6 \%$ biased estimates of lambda

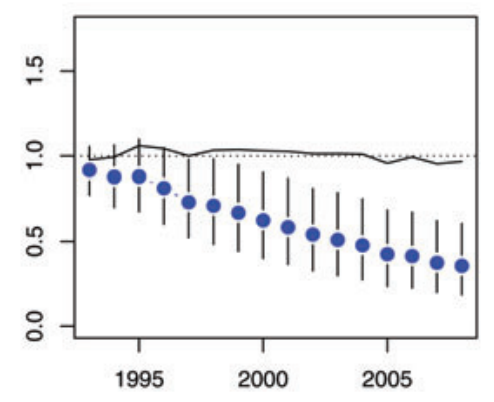

Figure 1. Expected growth (dotted line) and true realized growth (solid line) plotted for a single realization of a population. Overlaid are the sampling distributions of realized growth estimates; blue dots indicate the mean of the sampling distribution, and vertical bars show the central $95 \%$ of the distribution. Bias in annual $\lambda$ estimates varies from 0 (a) to $6 \%$ (d). In (a), the variability in realized growth estimates increases through time. With biased annual $\lambda$ estimates, bias in estimates of realized growth increases with interval length; the variability in the estimates simultaneously decreases so that estimated realized growth becomes an increasingly poor representation of reality. To produce this figure and explore sensitivity to various biases in survival and recruitment, refer to the program accessible at www.stat.ualberta.ca/ slele/publications/HB-1.sim.r.

mates every few years (Hatter and Bergerud 1991). Yet Boutin et al. and Latham et al. (2011) used this method, which has utility for comparing population growth over short time frames, to calculate realized population growth over a 16-year interval and incorporated neither population estimates nor potential biases in their vital rate estimators. This is problematic because relative bias in realized population change compounds annually over the entire interval. Even modest annual biases can result in substantial biases in realized population change over this extended time period. Sources of this bias include: non-random censoring (used when the exact status of an individual as "dead" or "undetectable" is unknown), differential visibility of cows and calves, calves misclassified as cows, collared animals misrepresenting pop- ulation age structure or survival rates, and misallocation of unknown adults to the incorrect sex. Most of these sources lead to negative bias, with considerable management implications. A mere $2 \%$ negative annual bias produces a $28 \%$ bias in the estimate over 16 years (Figure 1), and could simply be caused by an extra mortality in 30 collared individuals every other year. A positive bias will similarly accumulate in the opposite direction. Uncorrected negative and positive biases in estimates cause confidence intervals to shrink and expand, respectively (Panel 1). In contrast, realized population change calculation based on abundance estimates is more reliable because change measures are only affected by the bias and uncertainty in the first and last population estimates (Panel 1).

Likewise, Boutin et al. questioned 
our findings that human use negatively affected caribou, claiming that attempts by energy companies to consolidate secondary roads have had no effect on caribou declines; yet they failed to substantiate their assertion with data on management efforts or a reliable measure of caribou population decline or health.

In response to Boutin et al.'s contention that we did not sample long enough after oil crews departed to detect the reported reduction in physiological stress as human use declined, we counter that human-use levels have a negative effect on caribou across both temporal and spatial scales. The fact that physiological stress declined so rapidly during and after reduction in human activity only strengthens our argument.

Boutin et al. claimed that our nutritional measures are unreliable because 97 of the 104 animals captured during the month of February in the region did not show stress-related declines in body condition (Alberta Caribou Committee unpublished data); yet they provided no supporting evidence (eg sampling design, measures of body condition, or empirical analysis). In contrast, we demonstrated negative effects of human use on psychological and nutritional stress using glucocorticoid and thyroid hormone measures that were corroborated by independent resource selection analysis.

Furthermore, Boutin et al. asserted that we incorrectly quoted Schneider et al. (2010) as stating wolf removal is "the most effective tool to curb" caribou declines. Yet even Boutin et al. argued that wolf removal is necessary to allow caribou populations to increase because habitat protection and restoration are too slow. Unfortunately, they do not have the reliable estimates of population size needed to justify wolf removal and to determine the time horizon for caribou persistence.

Boutin et al. claimed that our wolf population data support hypotheses of apparent competition, changing predator-prey dynamics, and incidental predation. Again, we contend that Boutin et al. lacked reliable population size estimates for caribou and other interacting species needed to support this claim.

Finally, Boutin et al. attributed to us the statement that human use, not wolf predation, is the proximate cause of caribou declines. Rather, we suggested that the impacts of human use have been underappreciated in this ecosystem and its mitigation could alleviate the need for intentional wolf removal; such removal, with or without deer removal, will likely have serious adverse impacts on this ecosystem (Estes et al. 2011).

Wolf removal has been justified by biased projections of rapid caribou declines, which create a false sense of urgency. Without reliable estimates of caribou or wolf population sizes and/or changes, or of the degree to which wolf predation hinders caribou in the study area, the intentional removal of wolves or deer is unjustified. Caribou manage- ment should implement efforts to control human-use levels before resorting to such drastic actions (which, if undertaken, should be accompanied by additional years of sampling). Now that reliable monitoring tools are available, there is no excuse for implementing such extreme actions across the landscape.

Samuel K Wasser ${ }^{1 *}$, Jonah L

Keim $^{2}$, Mark L Taper ${ }^{3}$, and

Subhash R Lele ${ }^{4}$

${ }^{1}$ Center for Conservation Biology,

University of Washington, Seattle, WA*(wassers@u.washington.edu);

${ }^{2}$ Matrix-Solutions Inc, Edmonton,

Alberta, Canada; ${ }^{3}$ Department of

Ecology, Montana State University,

Bozeman, MT; ${ }^{4}$ Department of

Mathematical and Statistical Sciences,

Edmonton, Alberta, Canada

Anthony RG, Forsman ED, Franklin AB, et al. 2004. Status and trends in demography of northern spotted owls, 1985-2003. Wildlife Monogr 163: 1-48.

Estes JA, Terborgh J, Brashares JS, et al. 2011. Trophic downgrading of planet Earth. Science 333: 301-06.

Goodman LA. 1960. On the exact variance of products. J Am Stat Assoc 55: 708-13.

Hatter IW and Bergerud WA. 1991. Moose recruitment, adult mortality and rate of change. Alces N Am 27: 65-73.

Latham ADM, Latham MC, McCutchen NA, and Boutin S. 2011. Invading white-tailed deer change wolf-caribou dynamics in northeastern Alberta. J Wildlife Manage 75: 204-12.

Schneider RR, Hauer G, Adamowicz WL, and Boutin S. 2010. Triage for conserving populations of threatened species: the case of woodland caribou in Alberta. Biol Conserv 143: 1603-11.

doi:10.1890/12.WB.006

\section{Panel 1. Amplification of error and bias in application of the lambda method}

Estimated growth rate for interval $t$, denoted by $\hat{\lambda}_{t}$, can be represented as $\hat{\lambda}_{t}=\lambda_{t} \cdot\left(1+b_{t}\right) \cdot \epsilon_{t}$, where $\lambda_{t}$ is the true growth rate for the interval. Here $b_{t}$ is the relative bias in the estimator and $\epsilon_{t}$ is such that $E\left(\epsilon_{t}\right)=1$. Then estimated realized growth over a period of $T$ intervals is:

$$
\hat{G}_{T}=\prod_{t=1}^{T} \hat{\lambda}_{t}=\left\{\prod_{t=1}^{T} \lambda_{t}\right\}\left\{\prod_{t=1}^{T}\left(1+b_{t}\right)\right\}\left\{\prod_{t=1}^{T} \epsilon_{t}\right\}=G_{T} \cdot\left\{\prod_{t=1}^{T}\left(1+b_{t}\right)\right\} \cdot \prod_{t=1}^{T} \epsilon_{t} \quad \text { (Eq 1) }
$$

where $G_{T}$ is the true realized growth. If the annual estimates are made independently of each other, it follows that:

$$
\text { (i) } E\left(\hat{G}_{T}\right)=G_{T} \prod_{t=1}^{T}\left(1+b_{t}\right) \text { and (ii) } V\left(\hat{G}_{T}\right)>G_{T}^{2} \cdot \prod_{t=1}^{T}\left(1+b_{t}\right)^{2} \cdot \sum_{t=1}^{T} V\left(\epsilon_{t}\right) \text {, }
$$

regardless of the distribution of $\epsilon_{t}$ (Goodman 1960). Thus, both bias and uncertainty are always compounded over time. In contrast, when $\hat{\lambda}_{t}$ is based on estimates of population size, $\hat{\lambda}_{t}=\frac{\hat{N}_{t+1}}{\hat{N}_{t}}$, again, writing the estimated value as $\hat{N}_{t}=N_{t} \cdot\left(1+b_{t}\right) \cdot \epsilon_{t}$, the esti-
mator of the realized growth is:

$$
\hat{G}_{T}=\prod_{t=1}^{T} \hat{\lambda}_{t}=\frac{\hat{N}_{2}}{\hat{N}_{1}} \frac{\hat{N}_{3}}{\hat{N}_{2}} \cdots \frac{\hat{N}_{T}}{\hat{N}_{T-1}} \frac{\hat{N}_{T+1}}{\hat{N}_{T}}=\frac{\hat{N}_{T+1}}{\hat{N}_{1}}=\frac{N_{T+1}}{N_{1}} \frac{\left(1+b_{T+1}\right)}{\left(1+b_{1}\right)} \frac{\epsilon_{T+1}}{\epsilon_{1}}=G_{T} \frac{\left(1+b_{T+1}\right)}{\left(1+b_{1}\right)} \frac{\epsilon_{T+1}}{\epsilon_{1}} .
$$

The uncertainty in $\hat{G}_{T}$ depends only on the bias and uncertainty in the first and last population estimates and not on all intervening estimates. 